University of Nebraska - Lincoln

DigitalCommons@University of Nebraska - Lincoln

\title{
Mineral Element Analyses of Switchgrass Biomass: Comparison of the Accuracy and Precision of Laboratories
}

\author{
Kenneth P. Vogel \\ University of Nebraska-Lincoln, kvogel1@unl.edu \\ Rose Medill \\ USDA-ARS
}

Steven D. Masterson

USDA-ARS

Robert B. Mitchell

USDA-ARS, rob.mitchell@ars.usda.gov

Gautam Sarath

USDA-ARS, Gautam.sarath@ars.usda.gov

Follow this and additional works at: https://digitalcommons.unl.edu/usdaarsfacpub

Vogel, Kenneth P.; Medill, Rose; Masterson, Steven D.; Mitchell, Robert B.; and Sarath, Gautam, "Mineral Element Analyses of Switchgrass Biomass: Comparison of the Accuracy and Precision of Laboratories" (2017). Publications from USDA-ARS / UNL Faculty. 1965.

https://digitalcommons.unl.edu/usdaarsfacpub/1965

This Article is brought to you for free and open access by the U.S. Department of Agriculture: Agricultural Research Service, Lincoln, Nebraska at DigitalCommons@University of Nebraska - Lincoln. It has been accepted for inclusion in Publications from USDA-ARS / UNL Faculty by an authorized administrator of DigitalCommons@University of Nebraska - Lincoln. 


\title{
Mineral Element Analyses of Switchgrass Biomass: Comparison of the Accuracy and Precision of Laboratories
}

\author{
Kenneth P. Vogel,* Rose Medill, Steven D. Masterson, Robert B. Mitchell, and Gautam Sarath
}

\begin{abstract}
Mineral concentration of plant biomass can affect its use in thermal conversion to energy. The objective of this study was to compare the precision and accuracy of university and private laboratories that conduct mineral analyses of plant biomass on a fee basis. Accuracy and precision of the laboratories was tested by having all laboratories conduct mineral analyses on subsamples of the same set of standard switchgrass (Panicum virgatum L.) samples and a certified standard. Laboratories differed significantly in both accuracy and precision even though several used the same analysis method indicating that the differences among laboratories were due to within laboratory procedures and quality control. Laboratories should be using sample standards to monitor both precision and accuracy of their mineral analyses. It would be advisable for researchers submitting samples to service laboratories to replicate the unknown samples to determine precision and to include replicated standards among the submitted samples to determine accuracy.
\end{abstract}

\section{Core Ideas}

- Mineral concentration of plant biomass can affect its use in thermal conversion to energy.

- Precision and accuracy of laboratory mineral analyses of plant biomass can vary significantly.

- Standard samples need to be used to monitor laboratories precision and accuracy.
Published in Agron. J. 109:1-4 (2017)

doi:10.2134/agronj2016.08.0475

Received 25 Aug. 2016

Accepted 9 Dec. 2016

Copyright (c) 2017 by the American Society of Agronomy

5585 Guilford Road, Madison, WI 53711 USA

All rights reserved
B IOMASS OF ENERGY CROPS such as switchgrass can be converted to fuels using either saccrification and fermentation processes or thermal processes such as combustion, pyrolysis, or torrefaction. The mineral concentration of biomass can adversely affect its use in combustion boilers by causing boiler slagging and fouling (Miles et al., 1996; Fahmi et al., 2007). The primary alkali minerals of biomass, $\mathrm{Ca}, \mathrm{Mg}, \mathrm{K}$, and $\mathrm{Na}$, can also impact conversion via pyrolysis and torrefaction by impacting production yields and reaction processes (Fahmi et al., 2007; Saddawi et al., 2012; Patwardhan et al., 2010). Information on the mineral content of biomass is needed to develop optimal harvest times and procedures and to identify cultivars with low mineral concentrations at optimal harvest periods. Both cultivar and harvest stage are known to influence mineral concentration of biomass crops such as switchgrass (Dien et al., 2006; El-Nashaar et al., 2009; Lemus et al., 2002, 2009). Mineral concentration also could have an effect on feedstock prices.

There are several laboratory methods for determining mineral element concentration including flame atomic absorption spectrometry (FAAS), inductively coupled plasmic optical emission spectrometry (ICP-OES), inductively coupled plasma mass spectrometry (ICP-MS), and X-ray diffraction (XRD) or fluorescence (XRF) (Baernthaler et al., 2006, Knudsen et al., 1981). In a comprehensive study by Baernthaler et al. (2006) FAAS and ICP-OES were recommended as analytical methods for most minerals found in biomass. The FAAS, however, was not recommend to measure $\mathrm{Al}$ concentrations. However, no comparisons have been made among laboratories that conduct mineral analyses of forages and biomass to determine their accuracy and precision. Accuracy refers to the closeness of a measured value to a standard or known value. Precision refers to the closeness of two or more measurements to each other. Precision is independent of accuracy. It is possible to be very precise, but inaccurate, and vice versa.

The objective of this study was to compare the precision and accuracy of university and private laboratories that conduct mineral analyses of plant biomass on a fee basis. The accuracy and precision of the laboratories was tested by having all

K.P. Vogel (retired), S.D. Masterson, R.B. Mitchell, and G. Sarath, USDA-ARS, Grain, Forage, and Bioenergy Research Unit, 251 Filey Hall, Department of Agronomy and Horticulture, University of Nebraska-Lincoln, Lincoln, NE 68583-0937; R. Medill, USDAARS, Lincoln, NE 68583, currently Chemical Engineering student, University of Oklahoma, Norman, OK 73019. *Corresponding author (vogelkp61@neb.rr.com).

Abbreviations: ICP-OES, inductively coupled plasmic optical emission spectrometry; ICP-MS, inductively coupled plasma mass spectrometry; $\mathrm{HB}$, hot block digestion; MW, microwave digestion. 
laboratories conduct mineral analyses on subsamples of the same set of standard samples. One of the standard samples was a U.S. National Institute of Standards (NIST; http:// www.nist.gov) certified plant sample of ground tomato leaves (Solanum lycopersicum L.) for which certified mineral concentration values were available.

\section{MATERIALS AND METHODS}

Switchgrass standard samples were harvested in bulk at various maturities from established nurseries at the University of Nebraska's Agricultural Research and Development Center located $50 \mathrm{~km}$ west of Omaha, NE. The standard samples were labeled MPV1 to MPV5. The three cultivar Cave-in-Rock samples were harvested at pre-boot (MPV1), anthesis (MPV2), and post-frost (MPV3). The two Kanlow N1 samples were harvested at anthesis (MPV4) and post-frost (MPV5). Cave-in-Rock is an upland octaploid cultivar while Kanlow N1 is an experimental lowland strain selected from cultivar Kanlow for improved winter survival (Vogel et al., 2011; Casler et al., 2012). Following collection, the switchgrass biomass was air dried on greenhouse benches and ground in a Wiley Mill to pass through a 2-mm screen. The ground material for each standard was thoroughly mixed and then stored in sealed $18-\mathrm{L}$ containers. Three randomized and numerically coded 4-g subsamples of each standard were sent to each laboratory for analyses as a set of samples. Two replicate samples of a NIST standard sample, SRM 1573a, which consisted of ground tomato leaves was also included in the analyses set for each laboratory. This standard, which was purchased from NIST, was selected as the accuracy control for the study because its certified elemental mineral concentration was similar to the range of mineral concentration previously reported for switchgrass. The laboratory methods used by NIST are available at: http://www.nist.gov. The subsamples sent to each laboratory were selected randomly.
The laboratories selected for use in this study were both university and private laboratories that conduct fee testing of forage and biomass samples including mineral analyses. All of the laboratories used in this study except one used ICD-OES to measure mineral concentration (Table 1). The other laboratory used ICP-MS. Two digestion processes, hot block digestion (ICP-OES-HB) and microwave digestion (ICP-OES-MW) can be used to prepare samples for digestion prior to ICP-OES analyses. Four laboratories used the ICP-OES-HB method, one used MW digestion, and one did not specify the digestion procedure. Depending on the laboratory and its analyses packages, biomass samples were analyzed for the following minerals: Ca, P, Mg, K, Na, Fe, Zn, Cu, Mn, Mo, S, Cl, Al, B, $\mathrm{Co}, \mathrm{Cd}, \mathrm{Ni}, \mathrm{Pb}, \mathrm{Ti}, \mathrm{V}$, and $\mathrm{Si}$. For the purposes of this report, only the results of the $\mathrm{Ca}, \mathrm{P}, \mathrm{Mg}, \mathrm{K}, \mathrm{Na}, \mathrm{Fe}$, and $\mathrm{Zn}$ analyses are reported. Some laboratories did not analyze all of these minerals so complete data sets for some of the minerals are not available. For this report, the laboratories have been given alphabetical codes.

The data from all the laboratories was compiled into a data set which was used for statistical analyses. The effects of laboratory and sample were assessed using analyses of variance. Data were analyzed using SAS version 9.2 GLM (SAS Institute, 2012) in a complete factorial with laboratories and samples treated as fixed effects. The mean and standard deviation were calculated for each laboratory's analysis of each mineral using the results for the three replicate subsamples of all five switchgrass samples. The laboratory means and standard deviations were utilized to find the coefficient of variation $(\mathrm{CV}$ 's $=$ relative standard deviations or RSD's) for every laboratory's analysis of each mineral. The CV's of each laboratory were averaged to find the laboratory's mean CV \% which was used as a measure of the laboratory's precision. Each laboratory's mineral analysis of the tomato leaf standard was compared to NIST's certified

Table I. Mineral element composition of a National Institute of Standards and Technology (NIST) certified plant sample (SRMI573, tomato leaves) and the mean mineral element composition of the same sample as determined by seven different laboratories in a blind test with two replicates.

\begin{tabular}{|c|c|c|c|c|c|c|c|c|}
\hline Methodt & Laboratory & $\mathrm{Ca}$ & $\mathrm{P}$ & Mg‡ & $\mathrm{K}$ & $\mathrm{Na}$ & $\mathrm{Fe}$ & $\mathrm{Zn}$ \\
\hline & & & & & $\mathrm{mg}$ & & & \\
\hline & NIST values & 50,500 & 2160 & 12,000 & 27,000 & 136 & 368 & 31 \\
\hline ICP-MS & $A$ & $4 I, 324 *$ & 2766 & $10,132 *$ & $19,710 *$ & $243 *$ & $108 *$ & 10 \\
\hline ICP-OES & B & $59,977^{*}$ & 2443 & II,920 & 26,266 & $388 *$ & 371 & 33 \\
\hline ICP-OES-HB & $\mathrm{C}$ & $43,915^{*}$ & 1932 & $9,295 *$ & $24,678 *$ & 114 & $298 *$ & 27 \\
\hline ICP-OES-HB & $\mathrm{D}$ & $54,195^{*}$ & 2450 & II,265 & $29,250 *$ & & $308 *$ & 29 \\
\hline ICP-OES-HB & $E$ & 48,500 & 2200 & $10,600 *$ & 27,900 & $90 *$ & $315^{*}$ & 32 \\
\hline ICP-OES-HB & $F$ & $58,121^{*}$ & 2495 & 12,388 & I7,799* & 154 & 370 & 36 \\
\hline ICP-OES-MW & G & $57,498 *$ & 2269 & 11,912 & II,687* & $|3|$ & 354 & 31 \\
\hline Mean & & 51,837 & 2351 & 11,135 & 22,772 & 183 & 308 & 28 \\
\hline CV§ & & 1.2 & 15.1 & 2.6 & 1.8 & 3.5 & 3. & 25.0 \\
\hline$F$ test & & $250 * *$ & 0.98 & $26.4 * *$ & $419 * *$ & $525 * *$ & $170 * *$ & 3 \\
\hline
\end{tabular}

* Indicates the laboratory mean is significantly different than the NIST value as tested by Dunnett's test at $P \leq 0.05$

** $\mathrm{F}$ test indicates laboratory results for the NIST sample analyses are significantly different at the 0.01 level.

† ICP-MS = inductively coupled plasmic mass spectrometry, ICP-OES = inductively coupled plasmic optical emission spectrometry, ICP-OES-HB = inductively coupled plasmic optical emission spectrometry hot block digestion, ICP-OES-MW = inductively coupled plasmic optical emission spectrometry microwave digestion.

$\ddagger$ The value listed was provided by NIST for information only and is not a certified value.

$\S \mathrm{CV}$ is the coefficient of variation also known relative standard deviation (RSD). 
values to judge the laboratory's accuracy. Laboratory accuracy results were tested using Dunnett's $t$ test at $P \leq 0.05$ to determine if they were significantly different than the NISTs standards composition values (SAS Institute, 2012). Results that were significantly different than NIST's certified values were deemed inaccurate. Accuracy was ranked by using the number of times a laboratory's analyses of a NIST certified sample was significantly different than the NIST value expressed as a percentage which is an inaccuracy percentage.

\section{RESULTS AND DISCUSSION}

Laboratories reported significantly different results from the analyses of the NIST tomato leaf standard for $\mathrm{Ca}, \mathrm{P}, \mathrm{Mg}, \mathrm{K}$, $\mathrm{Na}$, and Fe but not for $\mathrm{P}$ or $\mathrm{Zn}$ (Table 1). The number of laboratories that had results that were significantly different than the NIST tomato leaf standard for each mineral were as follows: $\mathrm{Ca}$ (6), P (0), Mg (3), K (4), Na (3), Fe (3), and Zn (0) (Table 1). None of the laboratories had analyses results that were not statistically different than the NIST standard values for all minerals analyzed. Except for $\mathrm{P}$ and $\mathrm{Zn}$, the mineral analyses for many of the laboratories were relatively inaccurate.
There were significant mean differences among the switchgrass standards for each mineral averaged over laboratories for all minerals discussed in this report except for $\mathrm{Na}$ and $\mathrm{Zn}$ (Table 2). The differences in mineral concentration among the samples permit their use in estimating the precision of the laboratories analyses of the mineral element concentration of switchgrass biomass. There were significant differences among laboratories for all minerals in the analyses of the five switchgrass standard samples (Table 3). There were even differences among laboratories for $\mathrm{Na}$ and $\mathrm{Zn}$ for which there were no significant differences when analyzed over laboratories. There also was a large range in both means and standard deviations (SD) for all minerals (Table 3).

There were large differences in accuracy for the mineral analyses among the laboratories (Table 4). Accuracy is expressed as an inaccuracy percentage to obtain an overall accuracy and precision total and ranking by simply adding the inaccuracy $\%$ and precision $\mathrm{CV} \%$. There also were large differences in precision as measured by mean CV\% averaged over all mineral analyses for each laboratory (Table 4). There were very large differences for the total inaccuracy and precision percentages. The laboratories

Table 2. Mean mineral element composition of five switchgrass biomass standard samples which were analyzed by seven different university or private laboratories in a blind analyses with three replicates of each sample. The standard deviation of all analyses for each sample is in parenthesis.

\begin{tabular}{lccccccc}
\hline \multicolumn{1}{c}{ Sample } & $\mathrm{Ca}$ & $\mathrm{P}$ & $\mathrm{Mg}$ & $\mathrm{K}$ & $\mathrm{Na}$ & $\mathrm{Fe}$ & $\mathrm{Zn}$ \\
\cline { 2 - 8 } MPVI & $2508(614)$ & $2418(296)$ & $1338(268)$ & $14,059(3624)$ & $82(96)$ & $124(61)$ & $20(7)$ \\
MPV2 & $2325(695)$ & $656(127)$ & $1101(259)$ & $7,343(2044)$ & $82(100)$ & $107(57)$ & $19(20)$ \\
MPV3 & $2888(675)$ & $706(117)$ & $1291(294)$ & $5,701(1508)$ & $79(97)$ & $127(49)$ & $20(27)$ \\
MPV4 & $2475(659)$ & $1255(168)$ & $1217(223)$ & $9,053(2627)$ & $85(90)$ & $68(48)$ & $15(6)$ \\
MPV5 & $2862(649)$ & $909(176)$ & $904(207)$ & $6,434(2489)$ & $84(94)$ & $97(47)$ & $16(28)$ \\
& & & & & & & \\
Mean & 2611 & 1189 & 1170 & 8,518 & 82.0 & 105 & 18.0 \\
CV \% & 9.0 & 14.4 & 9.6 & 9.5 & 26.3 & 30.4 & 100.0 \\
F test & $23.9 * *$ & $379 * *$ & $49.9 * *$ & $355^{-1} * *$ & 0.18 & $11.7 * *$ & 0.40 \\
LSD 0.05 & 381 & 279 & 184 & 1,324 & $\mathrm{~ns} \dagger$ & 52 & $\mathrm{~ns}$ \\
\hline
\end{tabular}

** $F$ test indicates standard sample means are significantly different at the $0.0 \mathrm{l}$ level.

$\dagger \mathrm{ns}=$ not significant.

Table 3. Laboratory mean and standard deviation (SD) for mineral element composition of switchgrass standard samples. Each university or private laboratory analyzed three replicate subsamples of the same five standard samples.

\begin{tabular}{|c|c|c|c|c|c|c|c|c|}
\hline Methodt & Laboratory & $\mathrm{Ca}$ & $P$ & $\mathrm{Mg}$ & $\mathrm{K}$ & $\mathrm{Na}$ & $\mathrm{Fe}$ & $\mathrm{Zn}$ \\
\hline & & & & & $-\mathrm{mg} \mathrm{kg}^{-1}$ & & & \\
\hline ICP-MS & A & $2306(444)$ & I 344 (792) & 867 (193) & I I,847 (3849) & $146(53)$ & $51(28)$ & $27(12)$ \\
\hline ICP-OES & B & $|53|(361)$ & II5I (788) & $872(175)$ & 6,472 (3195) & $256(6)$ & $50(28)$ & $40(43)$ \\
\hline ICP-OES-HB & C & $2357(254)$ & $1006(585)$ & $1072(172)$ & 8,971 (3560) & $17(8)$ & $89(31)$ & II (3) \\
\hline ICP-OES-HB & $\mathrm{D}$ & 3066 (293) & $1267(660)$ & |49| (264) & $10,327(405 \mathrm{I})$ & & $|7|(65)$ & $12(4)$ \\
\hline ICP-OES-HB & $E$ & $2587(280)$ & II 40 (624) & $1253(168)$ & $10,060(38 I I)$ & 33 (15) & $147(25)$ & II (4) \\
\hline ICP-OES-HB & $\mathrm{F}$ & $3605(3 I I)$ & 1247 (669) & 1349 (176) & $6,763(2 \mid 6 I)$ & $23(10)$ & $122(44)$ & $16(6)$ \\
\hline ICP-OES-MW & G & $2829(269)$ & 1166 (694) & 1287 (193) & $5,187(1595)$ & $19(8)$ & $102(22)$ & II (4) \\
\hline Mean & & 2611 & 1189 & 1170 & 8,518 & 82 & 105 & 18 \\
\hline CV \% & & 9.0 & 14.4 & 9.6 & 9.5 & 26.0 & 30.4 & 100.0 \\
\hline$F$ test & & $116 * *$ & $6.10 * *$ & $68.4 * *$ & $134 * *$ & $311 * *$ & $31.0 * *$ & $5.70 * *$ \\
\hline LSD 0.05 & & 381 & 279 & 184 & 1,324 & 35 & 52 & 30 \\
\hline
\end{tabular}

** $F$ test indicates laboratory means are significantly different at the 0.01 level.

† ICP-MS = inductively coupled plasmic mass spectrometry, ICP-OES = inductively coupled plasmic optical emission spectrometry, ICP-OES-HB = inductively coupled plasmic optical emission spectrometry hot block digestion, ICP-OES-MW = inductively coupled plasmic optical emission spectrometry microwave digestion. 
Table 4. Rank comparison of accuracy and precision of mineral element composition analyses of five switchgrass standard biomass samples by seven different university or private laboratories. Accuracy is ranked by using the number of times a laboratory's analyses of a NIST certified sample was significantly different than the NIST certified sample value expressed as a percentage which is an inaccuracy percentage. Inaccuracy and precision percentage totals were used to rank laboratories for a combination of both accuracy and precision.

\begin{tabular}{|c|c|c|c|c|c|c|c|}
\hline Method $†$ & Laboratory & Inaccuracy & $\begin{array}{c}\text { Accuracy } \\
\text { rank }\end{array}$ & $\begin{array}{c}\text { Precision } \\
\text { mean }\end{array}$ & $\begin{array}{c}\text { Precision } \\
\text { rank }\end{array}$ & Total & Overall rank \\
\hline & & $\%$ & & CV \% & & $\%$ & \\
\hline ICP-MS & A & 71.4 & 7 & 38.68 & 7 & 110 & 7 \\
\hline ICP-OES & B & 28.6 & 1 & 46.63 & 6 & 75 & 4 \\
\hline ICP-OES-HB & C & 57.1 & 6 & 33.05 & 5 & 90 & 6 \\
\hline ICP-OES-HB & $\mathrm{D}$ & 50.0 & 5 & 31.74 & 4 & 82 & 5 \\
\hline ICP-OES-HB & $E$ & 42.9 & 4 & 30.17 & I & 73 & 3 \\
\hline ICP-OES-HB & $F$ & 28.6 & I & 31.73 & 3 & 60 & 2 \\
\hline ICP-OES-MW & G & 28.6 & I & 30.33 & 2 & 59 & 1 \\
\hline
\end{tabular}

† ICP-MS = inductively coupled plasmic mass spectrometry, ICP-OES = inductively coupled plasmic optical emission spectrometry, ICP-OES-HB = inductively coupled plasmic optical emission spectrometry hot block digestion, ICP-OES-MW = inductively coupled plasmic optical emission spectrometry microwave digestion.

$\ddagger C V$ is the coefficient of variation = relative standard deviation (RSD).

with the best overall rank were laboratories that had both small inaccuracy and precision percentages.

The two laboratories with the best overall rankings were laboratories $\mathrm{F}$ and $\mathrm{G}$. Both had the same accuracy percentage and had very similar mean CV\% for the switchgrass standards (Table 4). Both laboratories used ICP-OES but used different digestion procedures. The mean $\mathrm{CV} \%$ for these two laboratories for the following minerals was $\mathrm{Ca}(9.1 \%), \mathrm{P}(56.5 \%), \mathrm{Mg}$ (14\%), K (31.4\%), $\mathrm{Na}$ (43.2\%), Fe (28.8\%), and Zn (34.2\%). Laboratory precision differed with each mineral. Elements $(\mathrm{P}$ and $\mathrm{Zn}$ ) for which all laboratories had accurate results had relatively high $\mathrm{CV} \%$ which indicates that replicate samples are needed even for these elements in laboratory analyses. Four of the laboratories used the IDP-OES-HB procedure, but still differed in both accuracy and precision. The differences in accuracy and precision among laboratories can likely be attributed to within laboratory procedures and quality control. Laboratories should use sample standards to internally monitor both precision and accuracy and include the results of the sample standards as part of the sample analysis report. It would be advisable for researchers submitting samples to service laboratories to replicate the unknown samples to determine precision and to include replicated standards among the submitted samples to determine accuracy. Utilizing internal and external sample standards in the analytical process should enable researchers to make decisions on the reliability of data from their own or fee-based laboratories.

\section{ACKNOWLEDGMENTS}

Mention of trade names or commercial products in this publication is solely to provide specific information and does not imply recommendations or endorsement by the U.S. Department of Agriculture (USDA). The USDA is an equal opportunity employer. Funding for this research was from Agriculture Research Service, USDA project funds and from the Agriculture and Food Research Initiative Competitive Grant no. 2011-68005-30411, USDA National Institute of Food and Agriculture.

\section{REFERENCES}

Baernthaler, G., M. Zischaka, C. Haraldsson, and I. Obernberger. 2006. Determination of major and minor ash-forming elements in solid biofuels. Biomass Bioenergy 30:983-997. doi:10.1016/j. biombioe.2006.06.007

Casler, M.D., R.B. Mitchell, and K.P. Vogel. 2012. Switchgrass. In: C. Kole, CP. Joshi, and D.R. Shonnard, editors, Handbook of bioenergy crop plants. CRC Press, Taylor and Francis Group, Boca Rotan, FL p. 563-590.

Dien, B.S., H.G. Jung, K.P. Vogel, M.D. Casler, J.F.S. Lamb, P.J. Weimer et al. 2006. Chemical composition and response to dilute-acid pretreatment and enzymatic saccharification of alfalfa, reed canarygrass, and switchgrass. Biomass Bioenergy 30:880-891. doi:10.1016/j.biombioe.2006.02.004

El-Nashaar, H.M., G.M. Banowetz, S.M. Griffith, M.D. Casler, and K.P. Vogel. 2009. Genotypic variability in mineral composition of switchgrass. Bioresour. Technol. 100(5):1809-1814. doi:10.1016/j.biortech.2008.09.058

Fahmi, R., A.V. Bridgewater, L.I. Darvell, J.M. Jones, N. Yates, S. Thain, and I.S. Donnison. 2007. The effect of alkali minerals on combustion and pyrolysis of Lolium and Festuca grasses. Fuel 86(10):1560-1569. doi:10.1016/j.fuel.2006.11.030

Knudsen, D.R., R.B. Clark, J.L. Denning, and P.S. Pier. 1981. Plant analysis of trace elements by X-ray. J. Plant Nutr. 3:61-75. doi:10.1080/01904168109362818

Lemus, R., E.C. Brummer, K.J. Moore, N.E. Molstad, C.L. Burras, and M.F. Barker. 2002. Biomass yield and quality of 20 switchgrass populations in southern Iowa, USA. Biomass Bioenergy 23:433-442. doi:10.1016/S0961-9534(02)00073-9

Lemus, R., D.J. Parrish, and D.D. Wolf. 2009. Nutrient uptake by 'Alamo' switchgrass used as an energy crop. BioEnergy Res. 2:3750. doi:10.1007/s12155-009-9032-3

Miles, T.R., T.R Miles Jr., L.L. Baxter, R.W. Bryers, B.M. Jenkins, and L.L.Oden. 1996. Boiler deposits from firingbiomass fuels. Biomass Bioenergy 10:125-138. doi:10.1016/0961-9534(95)00067-4

Patwardhan, P., J. Satrio, R.C. Brown, and B.H. Shanks. 2010. Influence of inorganic salts on the primary pyrolysis products of cellulose. Bioresour. Technol. 101:4646-4655. doi:10.1016/j. biortech.2010.01.112

Saddawi, J.M., J.M. Jones, A. Williams, and C. Le Coeur. 2012. Commodity fuels from biomass through pretreatment and torrefaction: Effects of mineral content on torrefied fuel characteristics and quality. Energy Fuels 26:6466-6474. doi:10.1021/ ef 2016649

SAS Institute. 2012. SAS Version 9.2. SAS Inst., Cary, NC.

Vogel, K.P., G. Sarath, A.J. Saathoff, and R.B. Mitchell. 2011. Switchgrass. In: N.G. Halford and A. Karp, editors, Energy crops. The Royal Soc. of Chemistry, Cambridge, UK. p. 341-380. 